\title{
High Energy Radiation-Induced Aggregation of Plasma Proteins. Time Resolved Light Scattering Measurements
}

\author{
H. Kihara ${ }^{*}$ and W. Schnabel \\ Hahn-Meitner-Institut für Kernforschung Berlin GmbH, Bereich Strahlenchemie, Berlin \\ Z. Naturforsch. 35a, 217-220 (1980); received December 27, 1979
}

\begin{abstract}
Human immunoglobulin (IgG), bovine fibrinogen and bovine serum albumin were irradiated at room temperature with short pulses $(50 \mathrm{~ns}$ to $2 \mu \mathrm{s})$ of $16 \mathrm{MeV}$ electrons in $0.2 \mathrm{M} \mathrm{NaClO}_{4}$ solution containing phosphate buffer $\left(\mathrm{pH}\right.$ 7.5). In the presence of $\mathrm{N}_{2} \mathrm{O}$ the intensity of light (LSI) scattered by the protein solutions increased after the pulse indicating aggregation. The latter process originates from the attack of protein molecules by $\mathrm{OH}$ radicals (aggregation is impeded by t-butanol and augmented by $\mathrm{N}_{2} \mathrm{O}$ ). Upon plotting the relative increase of LSI vs. log time (after the pulse) sigmoidally shaped curves were obtained.

From these findings and results of optical absorption measurements the following is inferred: Aggregation occurs as a consequence of chemical alterations of the protein molecules induced by the attack by $\mathrm{OH}$ radicals. The transient species formed during and a few $\mu \mathrm{s}$ after the pulse are reacting within a period of several $\mathrm{ms}$. At the end of this period the formation of aggregates starts. It is concluded that the primary radiation chemical process consists (among others) in the generation of nucleation sites. The latter subsequently initiate aggregation processes.
\end{abstract}

\section{Introduction}

Kinetic and dynamic studies based on time resolved light scattering measurements concerning the change of size of macromolecules in solution have been carried out in our laboratory during the last years [1]. Those investigations were done by using the light scattering detection method in combination with the method of pulse radiolysis or flash photolysis. Predominantly synthetic polymers were used so far.

This paper reports first results obtained upon irradiating several proteins in dilute aqueous solu. tion with short pulses $(50 \mathrm{~ns}-2 \mu \mathrm{s})$ of $16 \mathrm{MeV}$ electrons. It has been reported $[2,3]$ that aggregation is the predominant effect observed upon irradiating proteins with ionizing radiation. Since the mechanism of aggregation is so far not understood, it was attempted to contribute to its elucidation by pulse radiolysis experiments in combination with time resolved light scattering measurements. Since the light scattering intensity (LSI) of a protein solution is expected to increase upon aggregation, it was expected that, this way, it should be possible to learn about the kinetics of aggregation.

* On leave from Jichi Medical School, MinamikawachiMachi, Tochigi-ken, Japan.

Reprint requests to Prof. Dr. W. Schnabel, Hahn Meitner Institut für Kernforschung Berlin GmbH, Bereich Strahlenchemie, Postbox 390128, D-1000 Berlin 39.
As is described below, the three plasma proteins investigated exhibited phenomenologically an analogous behavior with respect to aggregation.

\section{Experimental Part}

\section{(a) Materials}

The proteins were lyophylized samples. They were used without further purification. Human immunoglobuline (IgG) was obtained from Miles. It consists of a mixture of the types $\operatorname{IgG}_{1}, \operatorname{IgG}_{2}, \mathrm{IgG}_{3}$, and $\mathrm{IgG}_{4}$. The average molecular weight amounts to about $1.5 \times 10^{5}$. Bovine fibrinogen (95\% clottable) was also obtained from Miles. Its molecular weight is $3.4 \times 10^{5}$. Albumin (from bovine serum) was obtained from Boehringer (molecular weight: $\left.6.8 \times 10^{4}\right)$. For certain experiments t-butanol (Merck, p.a.) was used. $\mathrm{NaClO}_{4}$ (p.a.), $\mathrm{Na}_{2} \mathrm{HPO}_{4}$ (p.a.) and $\mathrm{KH}_{2} \mathrm{PO}_{4}$ (p.a.) were obtained from Merck. For the sake of purification water was allow. ed to pass a set of Millipore cartridges (ion exchange, super carbon and filtration cartridges).

\section{(b) Preparation and Irradiation of Samples}

Protein samples were dissolved several hours prior to irradiation in $10^{-2} \mathrm{M}$ phosphate buffer solution $(\mathrm{pH} 7.5)$ containing $\mathrm{NaClO}_{3}(0.2 \mathrm{~mol} / \mathrm{l})$. The solutions were saturated with either $\mathrm{Ar}$ or $\mathrm{N}_{2} \mathrm{O}$. The latter converts hydrated electrons to $\mathrm{OH}$ radicals 
$\left(\mathrm{e}_{\mathrm{aq}}^{-}+\mathrm{N}_{2} \mathrm{O}+\mathrm{H}_{2} \mathrm{O} \rightarrow \mathrm{OH} \cdot+\mathrm{OH}^{-}+\mathrm{N}_{2}\right)$. Some experiments were carried out with air-saturated solutions.

For the irradiations a flow system was used. The sample cell (quartz) was placed directly in front of the exit window of a L-band linear accelerator (Vickers). The samples were irradiated with single pulses of $16 \mathrm{MeV}$ electrons. The pulse duration was varied between $50 \mathrm{~ns}$ and $2 \mu \mathrm{s}$. The absorbed dose per pulse amounted from 4 to $150 \mathrm{krad}$. It was determined with the aid of the Fricke dosimeter.

For the light scattering measurements an argonion laser (Spectra Physics, Model 165-00, 1.2 W at $\lambda=514.5 \mathrm{~nm}$ ) was used. Details concerning the pulse radiolysis facility used (including the LS and the optical absorption detection system) have been described elsewhere $[1,4,5]$.

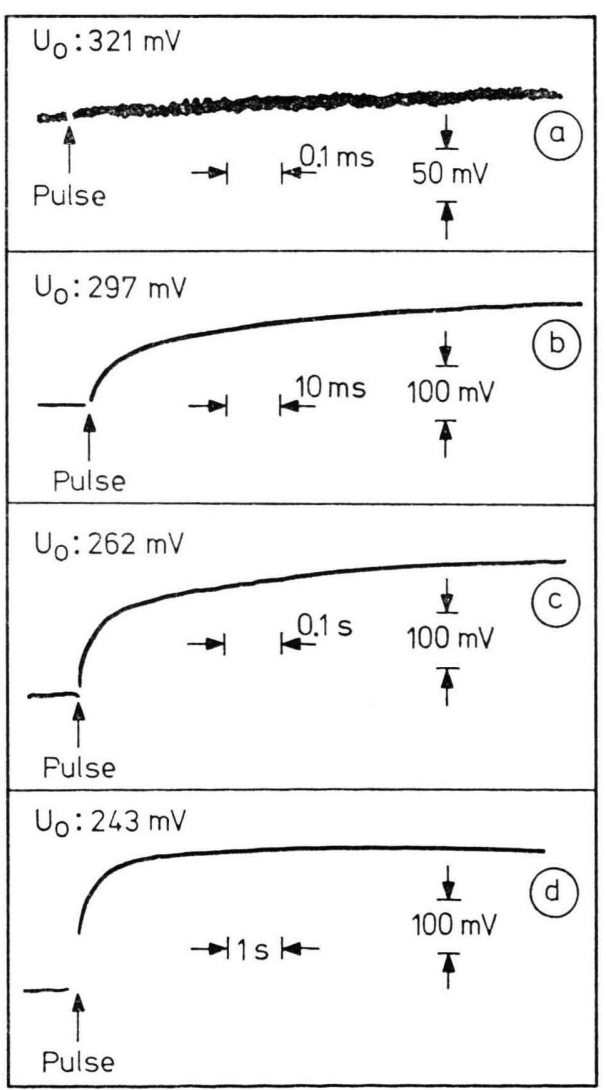

Fig. 1. Irradiation of $\operatorname{IgG}(2 \mathrm{~g} / \mathrm{l})$ in $\mathrm{N}_{2} \mathrm{O}$-saturated $10 \mathrm{mM}$ phosphate buffer solution $(\mathrm{pH} 7.5)$ at room temperature. $\left[\mathrm{NaClO}_{4}\right]$ : $0.2 \mathrm{M}$. Absorbed dose per pulse: $90 \mathrm{krad}$. Typical oscilloscope traces demonstrating the increase of LSI after the pulse as a function of time. The time scale increases from (a) to (d) as indicated in the graph.

\section{Results}

\section{(a) Light Scattering Measurements}

The three proteins exhibited an analogous behavior upon irradiation with an electron pulse in $\mathrm{N}_{2} \mathrm{O}$-saturated solution. Typical oscilloscope traces obtained with a $\operatorname{IgG}$ solution of $2 \mathrm{~g} / \mathrm{l}$ are depicted in Fig. 1, where one can see that the LSI increases steadily after the pulse. By using a logarithmic time scale sigmoidal curves were obtained demonstrating that the saturation value is reached in the range of seconds. Typical curves obtained with IgG and albumin are shown in Fig. 2 (a) and (b).

The extent of the LSI increase is increasing steadily with the absorbed dose per pulse as is shown in Fig. 3 for the three proteins. Upon prolonged irradiation aggregates precipitated in all cases. It appears

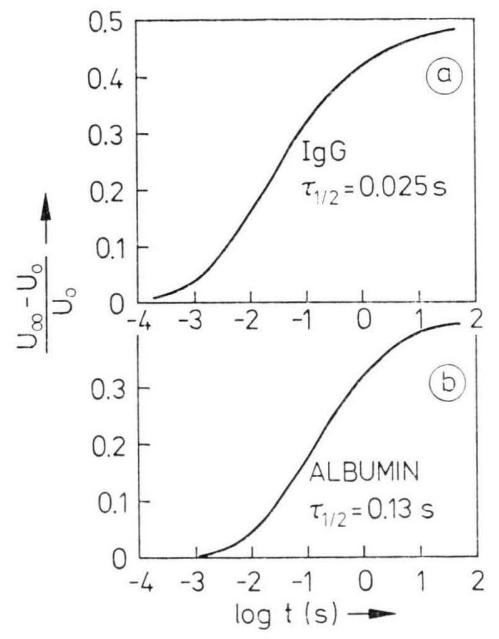

Fig. 2. Semilogarithmic plot demonstrating the increase of the LSI after the pulse as a function of time. $\mathrm{N}_{2} \mathrm{O}$ saturated solutions $(10 \mathrm{mM}$ phosphate buffer, $\mathrm{pH} 7.5$, $\left.\left[\mathrm{NaClO}_{4}\right]: 0.2 \mathrm{~mol} / \mathrm{l}\right)$ of (a) $\mathrm{IgG}(2 \mathrm{~g} / \mathrm{l}$, abs. dose per pulse $21 \mathrm{krad})$ and (b) albumin $(2 \mathrm{~g} / \mathrm{l}$, abs. dose per pulse: $42.5 \mathrm{krad})$.

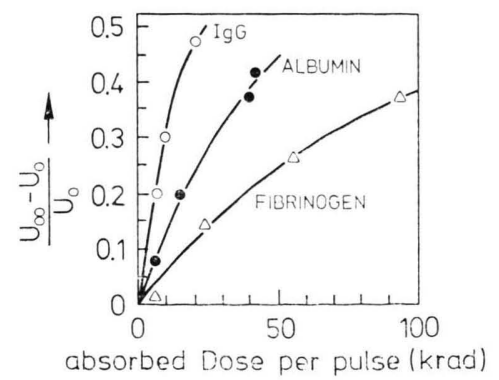

Fig. 3. The extent of LSI increase as a function of absorbed dose per pulse for $\mathrm{IgG}$, albumin and fibrogen in $\mathrm{N}_{2} \mathrm{O}$. saturated solution. Protein concentration $2 \mathrm{~g} / \mathrm{l}$. 
Table 1. Irradiation of immunoglobulin. Total extent of LSI increase at constant absorbed dose per pulse $(28 \mathrm{krad})$. IgG $(2 \mathrm{~g} / \mathrm{l})$ in $10^{-2} \mathrm{M}$ phosphate buffer (pH 7.5). $\left[\mathrm{NaClO}_{4}\right]$ : $0.2 \mathrm{M}$.

\begin{tabular}{ll}
\hline Condition $^{\mathrm{a}}$ & $\Delta U / U_{0} \mathrm{~b}$ \\
\hline $\mathrm{N}_{2} \mathrm{O}$ & 0.30 \\
$\mathrm{Ar}$ & 0.15 \\
$\mathrm{Ar}, \mathrm{t}$-butanol & \\
$\left(1.5 \times 10^{-1} \mathrm{M}\right)$ & 0 \\
$\mathrm{air}$ & 0 \\
\hline
\end{tabular}

a Solutions were saturated with the gas indicated.

b $\Delta U=U_{\infty}-U_{0} . \quad U_{0}$ and $U_{\infty}$ designate the signal voltages (proportional to the LSI) before and a long time after irradiation.

that the aggregation originates with the attack of the protein molecules by $\mathrm{OH}$ radicals. This is inferred from the following findings: If t-butanol (a scavenger for $\mathrm{OH}$ radicals) was contained in Ar-saturated solution at a sufficiently high concentration the formation of aggregates was suppressed. Typical results obtained with IgG are presented in Table 1 . It is seen that the total extent of the LSI increase observed in $\mathrm{N}_{2} \mathrm{O}$ saturated solution is augmented relative to that of the Ar-saturated solution, indicating that hydrated electrons are not becoming operative with respect to aggregate formation. (Due to the conversion of $\varepsilon$ aq to $\mathrm{OH}$ radicals, it is expected on the basis of the radiation chemical yields that the extent of the observed effect roughly doubles [6].)

In the presence of oxygen (i.e. in air-saturated solutions) the formation of aggregates was prohibited at relatively low doses per pulse $(<50 \mathrm{krad})$. At higher doses aggregation was observed. However, the total extent of LSI increase was much smaller than in Ar-saturated solution.

\section{(b) Optical Absorption Measurements}

These measurements were of importance with respect to two points: (i) Chemical reactions induced by the electron pulse might be detectable via the optical absorption of transients. The question, therefore, arose as to whether the rates of formation and/or decay of the transient absorption are correlated with the rate of aggregate formation. (ii) The LSI measurements were carried out at $\lambda=$

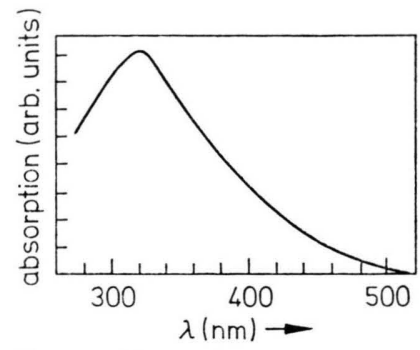

Fig. 4. Absorption spectrum measured at the end of a $2 \mu$ s pulse. Fibrinogen $(3 \mathrm{~g} / \mathrm{l})$ in $\mathrm{N}_{2} \mathrm{O}$ saturated $10 \mathrm{mM}$ phosphate buffer solution, $\mathrm{pH} \quad 7.5\left[\mathrm{NaClO}_{4}\right]$ : $0.2 \mathrm{M}$. Absorbed dose per pulse: $12 \mathrm{krad}$.

$514 \mathrm{~nm}$. Optical absorption changes in the scattering solution at this wavelength are reflected by the LSI detection system and might, therefore, lead to artifacts.

In all cases a transient absorption was formed during the pulse emerging at about $530 \mathrm{~nm}$ and increasing with decreasing wavelength in the observed range down to about $300 \mathrm{~nm}$. Absorption maxima between 320 and $350 \mathrm{~nm}$ were observed. A typical transient spectrum recorded at the end of a $2 \mu \mathrm{s}$ pulse in the case of fibrinogen is shown in Figure 4. At wavelengths below $400 \mathrm{~nm}$ the absorption decayed according to two modes corresponding to halflife times of 0.1 to $1 \mathrm{~ms}$ and 2 to $5 \mathrm{~ms}$, respectively. At higher wavelength only the slow mode of decay was observed. At $514 \mathrm{~nm}$ the absorption amounted only to a few per cent. The half-life time is significantly shorter (by one or two orders of magnitude) than the half-life times found for the formation of aggregates. Thus, the decay of the transient absorption certainly does not overlap with the strong increase of the LSI. Overlapping occurs, however, in the time range where the formation of aggregates starts, i. e. during the "nucleation" period.

\section{Conclusions}

The results obtained from the optical absorption measurements show: (a) During the period of significant LSI increase a transient at $514 \mathrm{~nm}$ does not influence the LSI measurements (b) Intermediates formed during and after the pulse are decaying at an early stage relative to the aggregation process. The light scattering measurements indicate the following: The curves depicting the LSI increase after the pulse are of sigmoidal shape. This strongly suggests that we are dealing here with aggregation processes proceeding analogously to those induced 
by other means [7]. It appears that the slow initiation period observed corresponds to the "nucleation" period usually found in the aggregation of proteins. The initiation period overlaps with the decay of the transient species. Therefore, it is concluded that ag. gregation occurs as a consequence of chemical alterations of the protein molecules induced by the attack of the latter by $\mathrm{OH}$ radicals

A transient absorption indicating lifetimes of protein radicals extending to the period of pro-

[1] W. Schnabel, Application of the Light Scattering Detection Method to Problems of Polymer Degradation, in: Development in Polymer Degradation 2. (N. Grassie, ed.) Appl. Science Publ. London 1979.

[2] K. Zakrzewski, M. Kłoczewiak, and M. Hay, Rad. Res. 53, 124 (1973).

[3] D. Rosen, Biochem. J. 72, 597 (1959).

[4] G. Beck, J. Kiwi, D. Lindenau, and W. Schnabel, Eur. Polym. J. 10, 1069 (1974). nounced aggregation was not detectable. Therefore, the possibility can be excluded that the aggregation is due to the combination of protein radicals.

\section{Acknowledgements}

The financial support of this work by Deutsche Forschungsgemeinschaft is gratefully acknowledged. The authors wish to express their thanks, furthermore, to Dr. G. Beck and Mr. M. Wilhelm for help and advice during the pulse radiolysis experiments.

[5] M. Grätzel, A. Henglein, and E. Janata, Ber. Bunsen. ges. Phys. Chem. 79, 475 (1975).

[6] See e.g. A. Henglein, W. Schnabel, and J. Wendenburg, Einführung in die Strahlenchemie, Verlag Chemie, Weinheim 1969.

[7] F. Oosawa and S. Asakura, Thermodynamics of the Polymerization of Protein, Academic Press, London (1975. 